\title{
Identification of Building Failure Indicators
}

\author{
Ali Raza Khoso \\ Department of Civil Engineering, Mehran \\ University of Engineering \& Technology, \\ Jamshoro, Pakistan \\ aliraza.khoso@faculty.muet.edu.pk
}

\author{
Jam Shahzaib Khan \\ Department of Civil Engineering, Quaid- \\ e-Awam University Of Engineering, \\ Science \& Technology, Pakistan \\ jam_shazaib@hotmail.com \\ Aftab Ahmed \\ Department of Civil Engineering, \\ ISRA University, \\ Hyderabad, Pakistan \\ aftab.sohail19@gmail.com
}

\author{
Muhammad Akram Akhund \\ Department of Civil Engineering, \\ ISRA University, \\ Hyderabad, Pakistan \\ akhund@42gmail.com
}

\author{
Rizwan Ullah Faiz \\ School of Civil Engineering, \\ Faculty of Engineering, Universiti \\ Teknologi Malaysia, Malaysia \\ rizwantn16@gmail.com \\ Faizullah Memon \\ Public Health Engineering Department, \\ Government of Sindh, \\ Mirpurkhas, Pakistan \\ fiaz.memon.1996@gmail.com
}

\begin{abstract}
A most frequent problem in the construction industry of Pakistan is the failure of structures, especially buildings, before their expected design life. Structural failure in buildings at the time of construction or after completion may result in human casualties, waste of money, social disturbance, and clashes, and claims between stakeholders. Many researches have already been conducted about key causes which lead a structure to fail at later stages. This research is pursuing to analyze early building failure indicators (BFIs) in Pakistan. Indicators and causes emerged from a thorough literature review, past projects, and site visits of various projects in Pakistan. The causes were grouped in sets of BFIs with the consent of structural experts. The collected data were analyzed in SPSS using mean value. Critical reasoning and conceivable recommendations are suggested by the opinion of experienced stakeholders having worked at various projects in Pakistan. The identification of these indicators is a key interest research topic for the country, as it would possibly reduce the failures of buildings in the future, saving lives, money, time, and conflicts among stakeholders.
\end{abstract}

Keywords-building failure indicators (BFI); construction projects; Pakistan; structural failure

\section{INTRODUCTION}

A structure may be a building, bridge, dam, retaining wall, sluice gate, etc. constructed from individual, interconnected, interrelated elements that are formed together with a system that can resist applied external load. This definition applies to much of what is seen in nature such as a fern leaf, an oak tree, shrub with ribbed branches, spider webs, etc. [1]. Structures are used for a wide variety of purposes, such as residential, institutional, commercial, industrial, and transportation. If any of the operational activities goes wrong or out of schedule, then it will lead to failure of the project [2] resulting in human casualties, delay, cost overrun, environmental disturbances, etc. [3]. Building failure is defined as a human act, or omission of occurrence or performance, lack of success, nonperformance, insufficiency, loss of strength, and cessation of proper functioning or performance $[1,4,5]$. Obviously, a building must be structurally safe, and the floors must be capable of resisting any normally imposed loads $[4,6]$. Defects can be the results of design errors, manufacturing flaws, defective materials, improper use or installation of materials, lack of adherence to the design, or any combinations among the above mentioned causes [6]. Initially, the causes reported on the uncertainties associated with structural failure during construction or after competition were divided into two groups: natural and man-made hazards [7]. Since no location is safe from natural disasters, efforts can be made to improve human errors up to a certain extend in order to avoid failures. In the past, many structural failures caused numerous human casualties, cost overrun, delays, contractor bankruptcies, etc. $\lceil 3,8\rceil$. Authors in $\lceil 9\rceil$ investigated the projects' failure in the perspective of cost escalation in Pakistan. Similarly, regarding road projects, authors in $[10,11]$ studied cost related problems in Pakistan. Authors in $\lceil 12\rceil$ investigated the projects structural issues in different countries including Pakistan and found that cost overrun and relevant failures are major problems. Several studies have been conducted to examine the events that precipitated such failures $[7,8,10]$. Structure failure is still a challenge for the construction industry, especially in developing countries, since the adaptation of sustainable construction through sustainable practices is very stagnant [13].

Construction in western countries concerns code practice compared to the Pakistani construction industry. During 20052006 a large amount of snow was accumulated in roofs in central Europe, and more than 50 cases of roof failure were reported in Germany, Austria, and Poland [14]. But these failures could be avoided if structures were designed to sustain extreme snow loads, as regulated in codes of constructions and build on sustainability grounds $[8,16]$. Authors in [1] report that the most common causes which lead a structure to failure are climate conditions, structure location, construction materials, building type, change in use, poor building maintenance, faulty design, corruption in construction, and lack of supervision. Failure in structure may occur at three stages of the building's life: construction, operation, and rebuilding, thus every stage failure may result in potentially dangerous unexpected accidents [17]. There is a stage wise failure of $58 \%$ 
at construction, $39 \%$ at operation and $3 \%$ at rebuilding, hence the risk of accidents is about $65 \%-70 \%$ more during the construction stage $[1,18]$. The impact of failure can be reduced in structures by providing good quality materials, sufficient manpower, good design and other favorable conditions that may increase the life of the structure [19]. The current research attempts to find those critical causes which lead to failure in structure within their designed life of the structure, in the local construction industry of Pakistan. In this regard, this study is a novel investigation, especially in local construction projects, since a limited number studies are done in this matter. The examined critical causes responsible for structural failures in building construction of Pakistan are thus confined in the set of Building Failure Indicators (BFIs). The identification of such indicators is helpful for concerned stakeholders to reduce any kind of failures in the future. The significance of these causes was analyzed by the Statistical Software Package SPSS using the mean method of the average index (AI). The data were collected on a five-point Likert scale. The mean values of critical causes were found with the help of SPSS as mentioned in Table II.

\section{RESEARCH METHODOLOGY}

The aim of this research is to investigate the causes of structure failures in Pakistan and to identify and study BFIs. Initially, an extensive literature review was carried out to determine the causative factors leading to building failure. The secondary data were gathered from published sources. To gather the primary data various construction sites in Pakistan were visited. Comprehensive sessions were conducted with experienced structural engineers and practitioners, construction managers, and site engineers to investigate the causative factors leading a structure to failure. Structured interviews with experts were carried out and finally 28 causative factors were identified. Those were grouped into seven BFIs. The questionnaire was developed and distributed to gather responses from technical personnel working in the construction industry. The results were then analyzed in SPSS, using the AI technique [15-20]. The grouping of significant causes was merged into BFIs and their causes and recommendations were examined at the second stage.

\section{DATA COLLECTION AND ANALYSIS}

A total of 115 questionnaires were distributed amongst professionals and experts. The response rate of the questionnaire survey is illustrated in Table I. Figures 1-2 show the demographics of the respondents. Figure 1 shows that clients, contractors, and consultants were targeted to gather the opinion of professionals. Figure 2 exhibits their experience level.

TABLE I. QUESTIONNAIRE STATISTICS

\begin{tabular}{|c|c|}
\hline Questionnaires distributed & 115 \\
\hline Questionnaires received & 71 \\
\hline Positive questionnaires for analysis & 65 \\
\hline Response rate & $56.5 \%$ \\
\hline
\end{tabular}

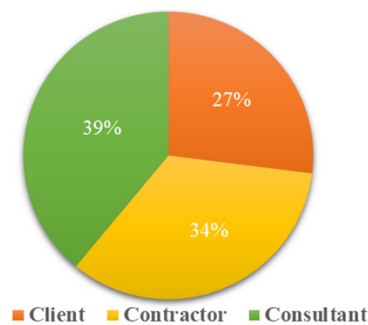

Fig. 1. Respondents' status

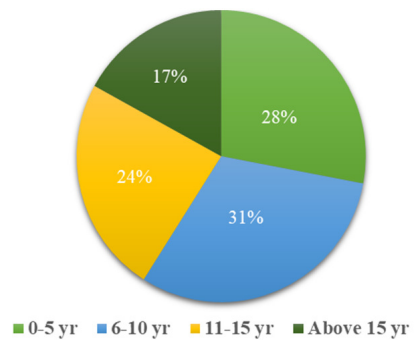

Fig. 2. Respondents experience

TABLE II. CRITICAL CAUSES OF BUILDING FAILURE IN PAKISTAN

\begin{tabular}{|c|c|c|}
\hline \multicolumn{3}{|c|}{ Indicators for Building Failure } \\
\hline Code & Material & AI \\
\hline MI 1 & Low-quality construction materials & 4.68 \\
\hline MI 2 & Erroneous quality control of materials & 4.04 \\
\hline MI 3 & Outlying material quarry from the construction site & 2.59 \\
\hline \multicolumn{3}{|c|}{ Quality Control } \\
\hline QCI 1 & Inadequate quality assurance by officials & 3.81 \\
\hline QCI 2 & Erroneous soil testing & 3.77 \\
\hline QCI 3 & Inadequate quality assurance system of construction & 3.77 \\
\hline QCI 4 & $\begin{array}{c}\text { Deterioration of structural components } \\
\text { due to delay in construction }\end{array}$ & 3.09 \\
\hline \multicolumn{3}{|c|}{ Design Code } \\
\hline DCI 1 & Contravening with standards codes of constructions & 4.04 \\
\hline DCI 2 & Indistinctive specifications & 3.54 \\
\hline DCI 3 & Construction of debile structures & 3.50 \\
\hline DCI 4 & On-site alterations & 3.04 \\
\hline \multicolumn{3}{|c|}{ Structural Inadequacy } \\
\hline SII 1 & Precluding soil in contact & 4.04 \\
\hline SII 2 & Inadequate connections & 4.00 \\
\hline SII 3 & Uneven soil settlement & 3.95 \\
\hline SII 4 & Miscalculating loads & 3.86 \\
\hline SII 5 & Inappropriate installation of structural members & 3.81 \\
\hline \multicolumn{3}{|c|}{ Project Management } \\
\hline PMI 1 & Ineffective functioning of machinery & 3.68 \\
\hline PMI 2 & Incompetent project manager & 3.54 \\
\hline PMI 3 & Frivolity of consultancy staff & 3.54 \\
\hline PMI 4 & $\begin{array}{l}\text { Inadequate communication among structural } \\
\text { team and contractors }\end{array}$ & 2.90 \\
\hline PMI 5 & $\begin{array}{l}\text { Indecisive to suggest remedial measures } \\
\text { for unanticipated problems }\end{array}$ & 2.86 \\
\hline \multicolumn{3}{|c|}{ Man Power } \\
\hline MPI 1 & Inefficient project team & 3.50 \\
\hline MPI 2 & Absence of key members & 3.50 \\
\hline MPI 3 & Unproductive labor & 3.45 \\
\hline MPI 4 & Untrained field inspector & 3.14 \\
\hline MPI 5 & Unqualified staff for modern technology & 2.36 \\
\hline \multicolumn{3}{|c|}{ Risk } \\
\hline RI 1 & Monetary turmoil & 3.77 \\
\hline RI 2 & Natural disasters & 2.86 \\
\hline
\end{tabular}




\section{RESULTS AND DISCUSSION}

The present study explores the critical causes of building failure in Pakistan construction projects. The examined causes were grouped into seven major classifications called BFIs. The mean sum of each category is calculated to prioritize the indicator. The analysis reveals that Structural Inadequacy indicator (SII) is the utmost cause in Pakistan with the highest mean sum of 3.93, followed by Material (MI) and Quality Control (QCI) indicators with 3.77 and 3.61 mean sum respectively. The other major indicators responsible for building failures in Pakistan are exhibited in Table III.

TABLE III. MOST CRITICAL BFIS IN PAKISTAN

\begin{tabular}{|c|c|}
\hline Building Failure Indicators & AI \\
\hline Structural Inadequacy (SII) & 3.93 \\
\hline Material (MI) & 3.77 \\
\hline Quality Control (QCI) & 3.61 \\
\hline Design Code (DCI) & 3.53 \\
\hline Risk (RI) & 3.32 \\
\hline Project Management (PMI) & 3.30 \\
\hline Man Power (MPI) & 3.19 \\
\hline
\end{tabular}

\section{A. Structural Inadequacy Indicator (SII)}

Every civil engineering structure is constructed on the ground, withstanding several loads. For this structure, the consideration of soil and its properties are essential to investigate. The purpose of soil is to withstand the load of the structure coming from the structural skeleton through the foundation. The soil requires sophisticated tests and experiments before constructing any structure over it. The bearing capacity of the soil and the chemistry of its layer must be investigated in the form of deep soil investigation. The load coming over the structure transpires the settlement in soil. Unequal settling of piers or footings of a foundation is an undesirable situation called uneven settlement which should be avoided. It occurs when the soil beneath the structure, contracts, expands or shifts away. Uneven settlement can be caused by drought conditions, vibration in nearby areas, improper load distribution, type of soil, etc.

Unfortunately in Pakistan no such detailed investigations are made on projects. The concept of deep soil investigation and several preliminary important parameters of structures are ignored. The interviews conducted with structural engineers and soil experts unfold that the owners of most of the projects or even government agencies are not fully aware of structural basic parameters and deep soil investigations. Another problem is the allocation of limited funds. For large projects, the client always hires, directly or indirectly, geotechnical consultants. But when the funds are limited, these investigations are fully omitted or narrowed down. The experts suggested that deep soil investigation is very essential and no design should be allowed to execute without it by a competent authority. Moreover, there is a strong need for social awareness regarding the importance of structure design and soil investigation. Therefore, an awareness program must be organized by the government. Finally, sufficient funds must be allocated for this important part of every project.

\section{B. Material Indicator (MI)}

It is a major issue in Pakistan construction projects. No doubt, specifications are provided to contractors during the contract, but it is mostly observed that the strictness towards quality control is poor. During the visit of a few projects, the engineers agree that the specifications are provided, but due to poor consultancy at the site, contractors are free to use poor materials. Although poor quality materials are cheaper, the durability of the building is reduced. There is no benefit of good design if the prime part of construction, i.e. materials, is of poor quality. So, proper material selection, handling and carrying out work as per standards will only lead towards safe implementation. In this regard, engineers interviewed at the site suggested that the client should follow a strict monitoring process. The client should not fully trust the consultants and should make routine visits at the site and call frequent meetings with consultants.

\section{Quality Control Indicator (QCI)}

Improper quality control system will put no benefits to the project. Defects and failure in constructed projects can result in very large costs. Even for minor defects, reconstruction may be required, which directly results in delay and augmented cost. Construction projects are composed of numerous interconnected activities, therefore it is not possible to construct a project lacking in terms of quality. To minimize quality control defects, certain teams and groups should be assigned with this task. It has been observed that quality is one of the leading issues in construction and results in poor-quality structures that fail before their design life. Generally, this is the sole responsibility of consultants on behalf of clients to look after. But, as discussed above, several times this part is ignored. A qualified engineer must be always available during the construction. But unfortunately, the sites are often handed to labor and engineers and other technical staff is not available even during the major execution part. Experts suggested that the clients themselves should visit the site on a regular basis and take timely progress reports from consultants to avoid this problem. More serious attitude from the client side could only open the direction of improvements.

\section{Design Code Indicator (DCI)}

Small carelessness could lead to serious problems and failure. A good team of workers, good quality materials, and advanced machinery, are useless if, work is not carried out according to standardized codes and specifications. This indicator is one of the most neglected parameters in most projects in Pakistan except the majority of mega projects. The contractors are not thorough in acquiring the true meaning of codes and specification resulting in feeble structures. It was revealed from the interviews that at construction site almost no one is aware of the standard codes. Even the engineers who are qualified experts don't take this part seriously. They follow their own traditional methodology just to save time and effort. The survey highlighted that many serious issues have occurred because of this cause. The experts reported that unfortunately, Pakistan has no proper codes for construction. The Pakistan Building Code is found to be not effective or trustworthy while mostly BS and ACI codes are followed by the industry. Even 
the proper use of such codes is not being followed in the construction leading to serious structure failures. This study suggests that the contractors need to train workers to operate as per specifications, and managers need to describe the complete tasks with clear concepts, before the start of any work. This will improve the skills of labor and put structure towards a safe site of construction.

\section{E. Risk Indicator (RI)}

The problem of the budget is one of the most common causes in every project. However, this is one of the leading and most common factors in almost every project in Pakistan. Several projects are found incomplete in major cities waiting for funds to be delivered. In some cases, even when the funds are released, the constructors are not getting their due payment at the right time due to other problems. These issues were found in most of the visited projects. The experts highlighted several funding problems that may become top risks for the constructors. The experts suggest that detailed planning must be conducted before executing the projects on these important monetary issues and certain rigid clauses must be added in the contractual agreement between parties. Apart from monetary risk, natural disasters are very common in different forms. A natural disaster can happen everywhere, but the severity of its effects can be reduced. Large buildings and other structures can survive powerful earthquakes if they are built with some level of flexibility. Pakistan is exposed to several potential disasters including floods, earthquakes, landslides, etc. The experts during the interviews explained that Pakistan is not working on natural disaster prevention effectively. In addition, during the design, no one is taking this part seriously. There is a need for detailed study on natural disaster management. If studies of this kind are implemented in Pakistan construction industry, the effect of natural disasters can be reduced considerably. The experts further pointed out that there is no check and balance for the structures against safety in such severe conditions. Proper construction methodology is not being followed and this may cause collapsing of structure even under small scale disasters. Thus, due care is required to avoid large scale disasters in Pakistan.

\section{F. Project Management Indicator (PMI)}

The management is of utmost important in every project. The management of stakeholders, the correct and rightly communication and machinery and its proper usage and suitability are equally important for a project. It is noticed that suitable machinery is often not being installed on the sites. The success of any project depends on the shoulders of the project manager, but unfortunately, incapable and inexperienced managers are common. Due to this, many project parameters are overlooked and cause many problems at a later stage. The right communications and relationships with stakeholders and especially with the consultants are most highlighted by experts. They suggest that the overall importance of project management and its core purpose is still not well understood to many construction stakeholders. Therefore, it was suggested that the project owner must be careful in this phase and ask from the constructors to provide detailed planning.

\section{G. Man Power Indicator (MPI)}

Man power plays a key role in a successful project. One cannot expect a positive and successful project from an imbalanced team. The stable combination of man power in terms of key personnel and other technical staff is highly demanding for a project. It was observed in the interviews that the hired labor on most of the projects is not well trained and the shifting of the technical staff and labors is a common issue. It was reported from the experts that the continuous changes of the project team are an issue. The absence of qualified professionals is a common problem. The hiring of unskilled filed inspectors and labors further hits the project negatively. Therefore, the latest use of technology is not seen on most of the projects. Workers feel more comfortable with traditional methods. The professionals recommend the constructors must train teams for different projects thus suitable training sessions must be ensured for all personnel. In order to avoid the problem of brain drain sufficient incentives other than their salary must be ensured and certain contractual agreements can further help to reduce this issue's impact.

\section{CONCLUSION}

The present study investigates the core causes of structural failures in Pakistan. After a literature review, structural experts in Pakistan were interviewed. The detailed analysis from the collected data presented the critical causes of structural building failure in Pakistan. The investigated causes were then grouped into a set of BFIs. Structural Inadequacy (SII), Material (MI), Quality Control (QCI), Design Code (DCI), Risk (RI), Project Management (PMI), and Man Power (MPI) are the major indicators responsible for several failures in building projects in Pakistan. It has been concluded that the building sector of Pakistan is not following proper construction standards. Quality is a major issue in every project in Pakistan. Soil testing and deep soil investigation are being neglected, proper structural design is not followed and implemented, and loads over the structure are not assessed properly. Moreover, sometimes natural disasters also damage the structures due to improper risk mitigating approaches. The second important aim of this research was to consider recommendations on such failure cause. Through detailed interviews with experts, possible solutions were provided and explained. The research findings can assist a client in executing future projects. The investigated BFIs of this study have gone some way towards contributing to the level of understanding and further avoiding any miss happens in the future.

\section{ACKNOWLEDGMENT}

Authors would like to express their gratitude to the Mehran University of Engineering \& Technology, Jamshoro, Pakistan.

\section{REFERENCES}

[1] M. K. Parfitt, "Why buildings fail: Are we learning from our mistakes?", Buildings, Vol. 2, pp. 326-331, 2012

[2] K. Wardhana, F. C. Hadipriono, "Study of recent building failures in the United States", Journal of Performance of Constructed Facilities, Vol. 17, No. 3, pp. 151-158, 2003 
[3] M. Sambasivan, Y. W. Soon, "Causes and effects of delays in Malaysian construction industry", International Journal of Project Management, Vol. 25, No. 5, pp. 517-526, 2007

[4] T. Z. Blaszczynski, P. W. Sielicki, "The influence of design and contractor errors on the failure of a tenement building”, Engineering Failure Analysis, Vol. 97, pp. 676-689, 2019

[5] J. M. Adam, M. Buitrago, "Learning from failures in an emblematic building in Valencia, Spain", Engineering Failure Analysis, Vol. 92, pp. 418-429, 2018

[6] L. M. Olanitori, "Causes of structural failures of a building: Case study of a building at Oba-Ile, Akure", Journal of Building Appraisal, Vol. 6, No. 3-4, pp. 277-284, 2011

[7] B. S. Olusola, O. Akintayo, "An assessment of failure of building components in Nigeria", Journal of Building Appraisal, Vol. 4, No. 4, pp. 279-286, 2009

[8] J. S. Khan, R. Zakaria, E. Aminuddin, N. I. Abidin, R. S. Sahamir, R. Ahmad, D. N. Abas, "Web-Based Automation of Green Building Rating Index and Life Cycle Cost Analysis", IOP Conference Series: Earth and Environmental Science, Vol. 143, Article ID 012062, 2018

[9] A. H. Memon, N. A. Memon, A. N. Laghari, M. A. Akhund, S. Ahmed, U. Imad, "Common factors of cost escalation in construction industry of Pakistan", Engineering, Technology \& Applied Science Research, Vol. 8, No. 6, pp. 3508-3511, 2018

[10] S. Sohu, A. H. Abdullah, S. Nagapan, A. A. Jhatial, K. Ullah, I. A Bhatti, "Significant mitigation measures for critical factors of cost overrun in highway projects", Engineering, Technology \& Applied Science Research, Vol. 8, No. 2, pp. 2770-2774, 2018

[11] S. Sohu, A. A. Jhatial, K. Ullah, M. T. Lakhair, J. S. Khan, "Determining the critical success factors for highway construction projects in Pakistan", Engineering, Technology \& Applied Science Research, Vol. 8, No. 2, pp. 2685-2688, 2018

[12] D. M. Mirzai, "Identifying the effective factors for cost overrun and time delay in water construction projects", Engineering, Technology \& Applied Science Research, Vol. 6, No. 4, pp. 1062-1066, 2016

[13] I. O. Adetunji, Sustainable Construction: A Web-Based Performance Assessment Tool, $\mathrm{PhD}$ Thesis, Loughborough University, 2005

[14] O. Hatherley, Building for Brexit: How Architecture Heralded the Failure of Project Europe, The Guardian, 2018

[15] M. A. Akhund, A. R. Khoso, J. S. Khan, H. U. Imad, K. M. Memon, "Prompting cost overrun factors during PCP in construction projects", Indian Journal of Science and Technology, Vol. 12, No. 4, pp. 1-7, 2019

[16] N. I. Abidin, E. Aminuddin, R. Zakaria, S. M. Shamsuddin, S. R Sahamir, J. Shahzaib, D. N. Abas, "Development of Weightage for Criteria Affecting in Retrofitting of Existing Building in Higher Learning Institution with Clean Energy Initiatives", IOP Conference Series: Earth and Environmetal Science, Vol. 143, Article ID 012033, 2018

[17] E. So, R. Spence, A. Khan, T. Lindawati, "Building Damage and Casualties in Recent Earthquakes and Tsunamis in Asia: A Cross-Event Survey of Survivors", 14th World Conferecne Earthquake Engineering, Bejing, China, October 12-17, 2008

[18] M. Buitrago, J. Sagaseta, J. M. Adam, "Effects of sudden failure of shoring elements in concrete building structures under construction", Engineering Structures, Vol. 172, pp. 508-522, 2018

[19] UN, Global Sustainable Development Report, 2015 Edition, Advance Unedited Version, UN, 2015

[20] A. R. Khoso, A. H. Memon, A. A. Pathan, M. A. Akhund, "Solid waste management issues in Hyderabad city", Mehran University Research Journal of Engineering and Technology, Vol. 37, No. 3, pp. 653-662, 2018 